\title{
Methode zur Ermittelung zeitlicher Variationen der Lothlinie.
}

\author{
Von Prof. E. Abbe.
}

In Nr. 3019 der Astr. Nachr. bespricht Hr. A. Nobile unter dem Titel »Note sur un appareil etc.» eine Einrichtung, welche darauf abzielt zu ermitteln, in wie weit an den neuerdings beobachteten Schwankungen der Polhöhe Veränderungen der Zenithlinie, also Schwankungen der Niveaufläche der Schwere gegen die feste Erdrinde, betheiligt sind.

Diese Mittheilung veranlasst mich, hier eine Methode kurz darzulegen, nach welcher diese Frage meines Erachtens auf wesentlich einfachere Art und mit grösserer Sicherheit des Erfolges zu eatscheiden sein wird. Ich würde selbst diese Methode schon in Ausfuhrung zu bringen versucht haben, wenn eine für den Zweck geeignete Localităt am hiesigen Ort zur Verfügung wäre.

Man denke sich einen gewöhnlichen Quecksilber- oder Oel-Horizont uberdeckt mit einer genügend dicken Glasplatte, die in nur drei Contacten möglichst direct auf dem festen Boden (natürichem Fels) frei aufliegt. Die Platte sei aus homogenem Glas, beiderseits vollkommen plan, aber in ganz geringem Maasse - um einige Bogensecunden keilförmig und durch Abgleichen der drei Auflagestellen sehr nahe parallel der Flüssigkeitsoberfläche gelagert.

Wenn nun in beliebigem Abstand ein Fernrohr mit Gaussischem Ocular auf den Horizont eingestellt wird, so erscheint das von der Flüssigkeitsoberfläche gespiegelte Bild des Fadenkreuzes dicht neben zwei Bildern, welche durch Reflexion an den planen Flächen der Platte entstehen. Eine mikrometrische Messung des jeweiligen Abstandes des ersteren Bildes von einem der beiden letzteren, oder von beiden, gestattet alsdann jede zeitliche Richtungsănderung der Flüssigkeitsnormalen, also der Lothlinie, gegen die Normale der mit der Erde fest verbundenen Spiegelfäichen nach Grösse und Azimuth zu bestimmen. - Durch die Reflexion wird jede Richtungsänderung auf dóppelte Grösse gebracht. Bei Anwendung einer Platte von genuigend grossem Durchmesser und eines entsprechend grossen Fernrohrs kann also jede gewünschte Genauigkeit der mikrometrischen Messung erreicht werden.

Statt, wie hier angenommen, ein Gaussisches Ocular zu verwenden, wird man ubrigens vortheilhafter eine geeignete leuchtende Marke in der Brennebene des Objectivs, aber etwas seitlich von der Axe desselben, anbringen z. B. eine feine kreisförmige Oeffnung in einem Silberniederschlag auf Glas, welche mittels eines Reflexionsprismas intensiveres Licht nach dem Objectiv hin sendet - und den Abstand der verschiedenen Spiegelbilder dieser Marke von einander messen. Ein für solchen Zweck geeignetes Mikrometer wäre sehr leicht herzustellen.

Jena 1891 Febr. 18.
Noch viel einfacher aber lüsst sich die Methode gestalten, wenn oberhalb des Flussigkeitshorizontes ein etwas hoher Raum zur Verfügung steht. In diesem Falle kann ein Fernrohr ganz entbehrt werden, wenn man an Stelle der erwähnten Planplatte eine plan-convexe Linse von langer Brennweite setzt, so gelagert, dass ihre nach unten gekehrte plane Flache der Flussigkeitsoberflkche nahezu parallel wird. In einer Höhe ubber der Linse gleich der Brennweite derselben wird dann - ohne jede Rohrverbindung, auf ganz getrenntem Gestell - die zuletzt erwăhnte Messvorrichtung (Marke und Mikrometer) sammt Ocular angebracht und der Abstand gemessen, welchen das von der Flüssigkeit gespiegelte Bild der Marke jeweils von dem an der planen Unterfiäche der Linse reflectirten Bild nach Grösse und Azimuth zeigt. Zur Beleuchtung wäre in diesem Fall eine Natronflamme zu benutzen, um die Farbenzerstreuung des Linsenglases ausser Spiel zu setzen; die sphärische Aberration aber ist dadurch unschädich zu machen, dass man die Brennweite der Linie sehr gross - mindestens gleich dem 60 fachen der freien Oeffnung - nimmt. Das zur Beobachtung dienende Ocular erhält, der langen Brennweite entsprechend, geringe Vergrösserung und das Mikrometer braucht entsprechend weniger fein zu sein. - Eine Einrichtung dieser letzteren Art würde besonders vortheilhaft sein bei Aufstellung des Horizonts in einem Schacht oder in dem Keller eines Gebăudes, in welchem die Beobachtung in einer oberen Etage, durch Oeffnungen in den Zwischendecken hindurch, geschehen kann.

Unveränderliche Aufstellung des Ocularapparates ist bei diesem 2weiten Verfahren offenbar ebensowenig erforderlich wie besonders feste Montirung des Fernrohrs bei dem ersten. Wesentlich ist nur, dass der angewandte Glaskörper Platte oder Linse - sich praktisch so verhalte wie eine an die feste Erdrinde selbst angeschliffene spiegelnde Facette. Diese Bedingung zu erfillen wird die einzige Schwierigkeit sein. Es wird dabei nicht nur darauf ankommen, dass eine ganz sichere und unwandelbare Anlagerung des Glases an ein dem Temperatur- und Feuchtigkeitswechsel nicht ausgesetztes Fundament erreicht werde, sondern zugleich darauf, dass die Beobachtungsstelle auch den mittelbaren Einwirkungen entzogen sei, welche Verschiebungen der benachbarten oberen Erdschichten in Folge wechselnder Temperatur und Durchfeuchtung ausuben können. Volle Sicherheit, dass eine etwa beobachtete Veräderung der Lothlinie nicht von solchen rein localen und zufulligen Veränderungen des Bodens an der Beobachtungsstelle herrührt, duirfte wohl kaum anders als durch correspondirende Beobachtungen an mehreren Orten zu gewinnen sein.

Notiz betr. Espin „A new variable star in Camelopardus" in A. N. 3023.

Der Stern DM. $+68: 3989^{\mathrm{m}} 35^{\mathrm{h}} 25^{\mathrm{m}} 22^{\mathrm{*}}+68^{\circ} 42^{\prime} \cdot 5$ ist beobachtet: Z. 1764 Sch. $185^{8}$ Nov. 12 $9.10^{\mathrm{m}}$, Z. 183 Ich. 1859 Mărz $99^{m}$.

E. Schönfeld. 